\title{
Psicoterapia de casal em um serviço-escola de Psicologia: uma ilustração clínica
}

\section{Couple psychotherapy in a psychological university clinic: a clinical illustration}

\section{Psicoterapia de Pareja en un servicio universitario de Psicología: una ilustración clínica}

\author{
Natalia Monti Di Osti* \\ Universidade Estadual de Londrina - UEL, Londrina, Paraná, Brasil \\ Maíra Bonafé Sei** \\ Universidade Estadual de Londrina - UEL, Londrina, Paraná, Brasil \\ Sandra Aparecida Serra Zanetti*** \\ Universidade Estadual de Londrina - UEL, Londrina, Paraná, Brasil
}

\begin{abstract}
RESUMO
Diversas são as estratégias de intervenção no campo da Psicologia Clínica e a psicoterapia de casal se apresenta como uma destas possibilidades. Entende-se que a psicoterapia psicanalítica de casal almeja auxiliar o casal a tornar conscientes conteúdos antes inconscientes, para que possam ser analisados e elaborados. Neste contexto, é importante a análise de mecanismos transferenciais, contratransferenciais, de resistência, além do fenômeno da transmissão psíquica geracional e os pactos inconscientes. Diante deste panorama, objetiva-se desenvolver um estudo teórico-clínico sobre a psicoterapia psicanalítica de casal, por meio da análise de um caso atendido em um serviço-escola de Psicologia. Dentre os resultados, por meio da compreensão da contratransferência, pôde-se perceber que a resistência do casal em debruçar-se em questões de caráter conjugal ligava-se ao fato de intuitivamente apreender que o pacto inconsciente que os mantinha juntos poderia se desfazer caso fosse desvendado e elaborado em terapia. Diante deste contexto, o artigo discute o trabalho que foi possível ser feito no processo terapêutico.
\end{abstract}

Palavras-chave: psicanálise, psicoterapia, casal.

\begin{abstract}
Several are the strategy interventions in the field of clinical psychology and couple psychotherapy present itself as one of these possibilities. It is understood that couple psychoanalytic psychotherapy aims to help the couple to become aware of content before unconscious so they can be analyzed and elaborated. In this context it is important to analyze transference mechanisms, countertransference, resistance, beyond the phenomenon of generational psychic transmission and unconscious pacts.
\end{abstract}


Faced with this panorama, the objective is to develop a theoretical and clinical study on couple psychoanalytic psychotherapy, through the analysis of a case treated at a psychological university clinic. Among the results, through the understanding of countertransference, it was possible to notice that the couple's reluctance to look into in conjugal character issues was linked to the fact that intuitively they could realize that the unconscious pact that kept them together could undo if it was stripped and elaborated in therapy. Given this context, the article discusses the work that was possible to be done in the therapeutic process.

Keyword: psychoanalysis, psychotherapy, couple.

\section{RESUMEN}

Varias son las estrategias de intervención en el campo de la psicología clínica y la psicoterapia de pareja se presenta como una de estas posibilidades. Se entiende que la psicoterapia psicoanalítica de pareja tiene como objetivo ayudar a la pareja a ser consciente de contenido antes inconsciente para que puedan ser analizados y elaborados. En este contexto, es importante analizar los mecanismos de transferencia, contratransferencia, la resistencia, más allá del fenómeno de la transmisión psíquica generacional y pactos inconscientes. Ante este panorama, el objetivo es desarrollar un estudio teórico y clínico de la psicoterapia psicoanalítica de pareja, a través del análisis de un caso tratado en un servicio universitario de Psicología. Entre los resultados, a través de la comprensión de la contratransferencia, se podía ver que la resistencia de la pareja para examinar las cuestiones de carácter conyugales estaba vinculada al hecho de intuitivamente darse cuenta de que el pacto inconsciente que los mantenía juntos podría deshacer si fuera pelado y elaborado en la terapia. Dado este contexto, el artículo aborda el trabajo que fue posible por hacer en el proceso terapéutico.

Palabras-clave: psicoanálisis, psicoterapia, pareja.

\section{Introdução}

\subsection{A psicoterapia psicanalítica de casal}

A psicoterapia de casais, de acordo com Dias (1990), surgiu após a Segunda Guerra Mundial, por meio de imensa preocupação de psiquiatras, assistentes sociais e diversos profissionais que perceberam um número elevado de separações entre os cônjuges na época. Por conta da guerra, muitos fatores - como deslocamentos, gerando traições nas famílias e miscigenações culturais, bem como a emancipação das mulheres - contribuíram para que muitos lares fossem desfeitos. Desta maneira, houve a necessidade, na época, de uma intervenção profissional para minimizar estes problemas.

Atualmente, muitas são as abordagens que embasam a prática da psicoterapia de casal. Na abordagem psicanalítica, a psicoterapia de casal possui a função de auxiliar o casal a desenvolver maneiras adequadas para que os conteúdos inconscientes se apresentem à consciência e, desta forma, possam ser analisados e elaborados dentro da dinâmica da conjugalidade (Benedito, 2004). Sendo assim, 
cabe ao terapeuta conduzir o processo analítico de forma a facilitar a análise e a elaboração dos conteúdos dos cônjuges, bem como promover a saúde emocional dos membros e não zelar pela manutenção ou ruptura do relacionamento. Entretanto, de acordo com Féres-Carneiro (1994), a ruptura do casamento pode acontecer, mesmo em decorrência do processo analítico, o que pode ser muito significativo e gerar mudanças em ambos ou em um dos membros em terapia.

Muitas vezes, a terapia de casal inicia-se com a terapia familiar, englobando os demais familiares no processo analítico. Diferentes são as demandas trazidas pela família que retratam o conflito relacional: há casos de combinação de queixas individuais; de queixas de um dos membros do casal sobre o outro; de questões referentes à parentalidade; bem como, de queixas que recaem apenas sobre um membro da família: o sujeito sintomático - o portador do sintoma na família - aquele que acaba sendo o encarregado de possuir o sintoma, dando a falsa ilusão ao grupo de que, caso tal familiar melhore, todos melhorariam sem que os demais fizessem muito esforço (Dias, 1990). Desta forma, Féres-Carneiro (1994) aponta que cabe ao terapeuta perceber quem é o paciente a ser analisado. Muitas vezes, no decorrer das sessões, observando-se que a demanda se refere mais ao casal que ao paciente identificado ou à família como um todo, o indivíduo sintomático deixa de ser o tema principal e conflitos conjugais começam a aparecer. Sendo assim, o terapeuta deve estar atento para fazer indicações a uma possível terapia de casal.

As indicações mais comuns para uma terapia de casal, segundo Gomes e Levy (2010), referem-se a conflitos em que os membros responsabilizam a relação ou o parceiro como o foco do sofrimento, nos quais as demandas, por vezes, revelam uma relação simbiótica ou muito conflitiva e/ou agressiva. Ocasionalmente, de acordo com as autoras, alguns casais em terapia revelam muitos conflitos de ordem parental, sendo, então, melhor orientados no contexto da terapia familiar. No entanto,

em alguns casos observa-se que a parentalidade oculta dificuldades em relação à conjugalidade, que deveriam ser prioritariamente trabalhadas. São situações nas quais os cônjuges não conseguem manter os lugares de homem e mulher, de marido e esposa, mas perdem-se nos lugares de pai e mãe. Frente a essa dinâmica, justifica-se que o encaminhamento feito seja o de uma terapia de casal. (Gomes \& Levy, 2010, p.15)

Gomes e Levy (2010) apontam que um fator indispensável para que ocorra a terapia de casal é que os parceiros reconheçam suas 
demandas e tenham consciência dos conflitos conjugais. Neste processo, será possível verificar como se constituiu a dinâmica do casal, de que forma se organizam, para que se possa localizar os motivos de um sintoma e isto ser trabalhado em terapia.

Alguns elementos da formação do casal são essenciais para que este se defina como tal, e, em contrapartida, distorções desses parâmetros podem indicar uma organização sintomática. Para Donnamaria, Nascimento e Terzis (2010) um casal deve se organizar em termos de: cotidianidade - ou seja, de estabilidade espaçotemporal, pois a convivência é que caracteriza a relação como um casamento; o projeto vital compartilhado - que se caracteriza como realizações e conquistas futuras desejadas pelos membros; relações sexuais - não se limitando apenas à atividade genital em si; e a tendência monogâmica - remetendo-se à preferência dos membros por preservar a relação com apenas um cônjuge. Além disso, outros fatores, inconscientes, podem ser elencados como caracterizadores de um casal, isto é, amparando as relações contratuais temos os pactos inconscientes estabelecidos entre os membros do casal.

Pensa-se que tais pactos inconscientes podem ser compreendidos como uma incorporação de traços dos parceiros entre si, sendo que tal traço passa a trabalhar como o próprio traço: é uma permuta de aspectos incompartilháveis que definem e mantém o vínculo (Donnamaria et al., 2010). Do mesmo modo, Féres-Carneiro (1994) aponta que as uniões se justificam por não existirem sujeitos totalmente constituídos por $\mathrm{si}$, na qual a conjugalidade se funda sobre as áreas do ego mais mal definidas de cada um.

O pacto denegativo é o pacto inconsciente que fundamenta o estabelecimento das uniões entre os parceiros. Para Kaës (2005), este pacto tem a função de manter unida uma família, um grupo ou um casal, porque se trata justamente do pacto inconsciente entre os psiquismos de manter sob recalque tudo aquilo que não pode ser tolerado pelos membros da união. Assim, é um pacto organizador dos vínculos, mas de caráter defensivo (Kaës, 1991). O que o autor afirma, portanto, é que estes processos inconscientes mantém os sujeitos unidos porque retiram desta ligação um benefício.

Para se entender a dinâmica da conjugalidade, torna-se necessário entender como são realizadas as escolhas amorosas e como as relações são estruturadas. Segundo Freud (1966), as escolhas baseiam-se em duas formas: a narcísica e a anaclítica. Na escolha narcísica, o indivíduo escolhe um parceiro que se assemelha ao que ele próprio é, ao que ele próprio foi, ao que gostaria de ser, ou até mesmo um alguém que um dia foi parte dele mesmo. Isto é, na escolha narcísica a pessoa busca a ela mesma no outro, entendendose que tais escolhas advêm de perturbações no desenvolvimento libidinal do indivíduo. Na escolha anaclítica, o indivíduo ama a pessoa que o alimentou, cuidou e protegeu e, desta forma, permitiu seu 
equilíbrio narcísico. Com isso, a escolha anaclítica abrange os indivíduos que tomam como referência os primeiros objetos amorosos em suas vidas.

Berenstein e Puget (1993) debruçaram-se sobre o tema de forma mais profunda e apontam que as estruturas conjugais podem se organizar de três formas: estrutura dual, terceridade limitada e terceridade ampla.

Em relação à primeira, estrutura dual, trata-se da elaboração de um vínculo que se mantém como uma "fusão", em que há idealização de ambas as partes e há diferença por possibilidades de simetria ou assimetria estável, em que os membros mantêm o parceiro em exclusividade, não havendo possibilidade de substituição e onde a ausência de um dos membros, resultaria em uma ameaça de aniquilação do outro. Em relação à simetria - ou gemelaridade - há ainda dois tipos: a erotizada e a tanática. Na primeira, o casal tende a definir-se como ser único, o projeto vital também é único e limitado, além de haver um pacto pela imobilização do tempo, para que o vínculo se mantenha sempre de forma igual. De forma geral, caracterizam-se conflitos de cunho sexual - pois em uma relação é necessário haver o reconhecimento das diferenças em relação ao outro - e a tendência monogâmica é necessária entre o casal. Em relação à segunda, tanática, também ocorre dependência máxima, contudo, produtora de mal-estar. Os membros realizam-se sobre as fantasias que possuem um sobre o outro, na tentativa de manter afastado aquilo que os frustrem - o real. A cotidianidade produz malestar e a tendência monogâmica é mantida. Já na assimetria estável - ou complementaridade enlouquecedora - o casal realiza um contrato de não-agressão, em que há a ideia de concessão. A cotidianidade e o projeto vital são o resultado de apenas uma das partes, as relações sexuais são de ordem pré-genital e a tendência monogâmica é mantida (Puget \& Berenstein, 1993).

A terceridade limitada, de acordo com os autores supracitados, é caracterizada por um terceiro ocupante em um lugar de excluído. Tal estrutura assemelha-se à primeira, mas não se mantém autossuficiente. O terceiro é necessário à relação e pode ocupar diferentes posições: sobre a ótica do funcionamento pervertedorpervertido, o terceiro é o observador impotente: é utilizado pelo casal apenas para triangular a relação e não sucumbir enquanto casal. Neste caso, a sexualidade caracteriza-se como insatisfatória, o cotidiano é idealizado por ambos, o projeto vital gira ao redor de uma possível separação, que não acontece e a tendência monogâmica não se mantém. Sob a ótica do funcionamento enciumante-ciumento, um dos membros é visto pelo outro como unido a um terceiro. Em relação ao funcionamento hiperdiscriminação, algumas divergências dificultam a cotidianidade, há escassas relações sexuais, o projeto 
vital é constituído de dois projetos individuais e a tendência monogâmica não é mantida.

Sobre a terceridade ampla, os autores apontam que há dois sujeitos discriminados, com representação interna do outro. Há comunicação entre o casal e o que é compartilhado entre os dois possui significados diferentes a respeito do comum, onde recortes podem ser realizados sem o receio da quebra do vínculo. A cotidianidade é positiva, o projeto vital compartilhado inclui o terceiro e há elaboração de um possível sentimento de exclusão. As relações sexuais envolvem diferenças em relação ao desejo de ambos e a tendência monogâmica é elaborada (Puget \& Berenstein, 1993).

\subsection{A transmissão psíquica}

Sabe-se que o ambiente compartilhado pelos componentes de um mesmo grupo, principalmente no que se refere à questão familiar ou conjugal, contém elementos intersubjetivos que são transmitidos psiquicamente entre os membros. Tais elementos fazem parte da dinâmica atual familiar ou conjugal, e/ou são pertencentes a um contexto anterior. Para a psicanálise de casal e família, o grupo precede o sujeito do grupo e, quando este nasce, é inevitavelmente inserido em um espaço, um conjunto subjetivo que mantém o sujeito - ou grupo - como herdeiro dos desejos, renúncias e recalcamentos dos grupos precedentes, como sugere Kaës (2001). Para este autor, este sujeito, da herança, está dividido, "como o sujeito do inconsciente, entre a necessidade 'de ser um fim para si mesmo' e de ser 'o elo de uma cadeia à qual está sujeito sem a participação da vontade'" (Kaës, 2001, p. 11). Pelo fato do grupo preceder o sujeito do grupo, o sujeito deve servi-lo, mas por isso pode igualmente esperar tirar benefícios.

Sendo assim, a família e as instituições, em geral, são os responsáveis por designar lugares, apresentar objetos, ritos e ideologias e traçar limites. É através deste grupo que o sujeito se constitui como é e se torna sujeito. Ele herda conteúdos predispostos e possui a tarefa de construí-los, organizá-los e transformá-los, o que Kaës denomina como "aquisição apropriativa" da herança. Tal aquisição não é totalmente passiva e há uma reconstrução da mesma na passagem de uma geração a outra. (Kaës, 2011).

Merli (2012), embasada pela teoria de Kaës, aponta que a transmissão psíquica se refere a um conjunto de questões que vão além das diferenças entre gerações e se caracterizam sobre os interditos, do recalque dos desejos e da culpa. Tais transmissões referem-se às identificações projetivas e introjetivas com o objeto de desejo e caracteriza-se como um processo de obtenção de um lugar de pertencimento entre os vínculos geracionais. Correa (2004) aponta que existem dois tipos de transmissão psíquica: a intergeracional e a 
transgeracional. A primeira, intergeracional, consiste no conteúdo elaborado psiquicamente pela geração atual, que será passado à geração posterior. Podem ser definidos como costumes, valores e crenças e o material é da ordem do consciente. A transmissão transgeracional é aquela cujos conteúdos não são elaborados, são indizíveis, impensáveis e inconfessáveis, transmitidos inconscientemente aos seus membros. Tudo aquilo que foi vivido em uma geração será transmitido à próxima, de forma consciente ou inconsciente.

A transmissão psíquica refere-se a padrões que se repetem de geração em geração e apresentam continuidade nos sentimentos inconscientes a eles ligados. O processo de transmissão psíquica entre gerações solicita um trabalho psíquico inconsciente constante de elaboração e transformação e, sendo o grupo familiar um espaço permeado de alianças e pactos inconscientes, a transmissão envolve um acordo inconsciente que assegura a continuidade do investimento libidinal de autoconservação para cada sujeito e também para o conjunto familiar-social ao qual está inserido (Correa, 2004).

O processo patológico da transmissão psíquica ocorre quando não há possibilidade da simbolização dos traumas vividos pelo grupo ou membro. Aqueles conteúdos sujeitos a silêncios e segredos continuam ativos na vida do indivíduo ou grupo, presentes no inconsciente como um processo "vivido não vivido e sempre a reviver", como citado por Winnicott (1963). No entanto, apesar do aspecto patológico, a transmissão pode ser positiva, pois uma geração não pode existir sem a que a precede e ainda deve-se criar outra para que a vida do grupo se perpetue (Gutierrez, Castro \& Pontes, 2011).

\subsection{Fenômenos implicados na psicoterapia de casais}

\subsubsection{A resistência}

Apontado por Freud desde os seus "Estudos sobre a histeria" (18931895), o conceito de resistência é caracterizado como uma força que se manifesta como um obstáculo à análise, em que o paciente adquire formas de defender seus sintomas. Sendo assim, o analisando bloqueia-se a toda e qualquer mudança ou transformação subjetiva proveniente do processo analítico. De acordo com Ventura (2009), é ideal que o analisando, juntamente ao analista, trabalhe e supere suas resistências para que qualquer tipo de mudança seja efetivada.

Em relação à psicoterapia de casal, em que os cônjuges possuem pactos inconscientes com conteúdos difíceis de serem trabalhados por ambos, a resistência também aparece. De acordo com Levy (2013), sabe-se que a conjugalidade reforça a gratificação parcial de desejos 
dos membros da relação, de forma que qualquer intervenção passível de causar alguma mudança pode ser sentida como ameaçadora ao casal. Sendo assim, as resistências ao tratamento em psicoterapia de casal se apresentam quando a aparente estabilidade é questionada. Tais impasses ocorrem na clínica por diversos motivos, como quando uma das partes ou ambas não estão totalmente mobilizadas ou implicadas no tratamento, ou ainda porque encontraram um equilibro inconsciente baseados um no sofrimento psíquico do outro (Levy, 2013).

As reações defensivas ao tratamento podem se mostrar de diversas maneiras: atrasos às sessões; dificuldades de se falar sobre o casal; culpabilização do sofrimento psíquico de um membro ao outro; imobilização do terapeuta; e até mesmo utilizar da transferência para realizar alianças com o terapeuta, de forma a inviabilizar a continuidade real do tratamento. Ademais, Levy (2013) aponta que

É comum a problemática de um dos cônjuges ser utilizada pelo outro para justificar o conflito manifesto, principalmente quando os limites individuais são pouco claros e o imaginário atravessa e distorce a percepção da realidade. O conflito subjacente provoca resistência. Impasses ocorrem na clínica porque os cônjuges nem sempre estão mobilizados ou implicados no tratamento ou ainda porque encontram um equilíbrio inconsciente graças à doença ou ao sofrimento do outro (Levy, 2013, p. 33).

Desta forma, diante do desconhecido, de uma aproximação vivida como invasiva no tratamento e de uma possível perda ou abalo no equilíbrio homeostático alcançado pelo casal, há a possibilidade do casal reagir com repertório defensivo na tentativa de imobilizar o terapeuta (Levy, 2013).

\subsubsection{Transferência e contratransferência}

Os conceitos de transferência e contratransferência são centrais na compreensão do vínculo terapêutico em diversas vertentes da psicanálise. $O$ processo da transferência, antes identificado por Freud como um obstáculo à análise - assim como a resistência - passou a ser visto como um fenômeno necessário ao processo analítico. De acordo com a teoria freudiana, a transferência se refere a desejos inconscientes que se atualizam na figura do analista como forma de repetir o modelo infantil de outros objetos, mas com sentimentos atuais; isto é: uma série de experiências psíquicas revividas, não como algo no passado, mas como vínculo atual com o terapeuta (Isolan, 2005). 
Usando a referência kleiniana, Pimentel e Barros (2009) apontam a importância da transferência por ela revelar, no presente, como o funcionamento psíquico do sujeito se configurou. A transferência tem de ser considerada a partir de um referencial interno, inconsciente, onde os objetos já introjetados permanecem influenciando a vida psíquica do sujeito. Importante ainda ressaltar a dualidade dos objetos introjetados, uma vez que eles são bons ou maus de acordo com as experiências próprias do sujeito. O conceito de transferência positiva e negativa - já colocados por Freud - instauram-se em terapia onde são revistas/reencenadas as relações objetais positivas e negativas com o analista. Cabe ao analista, mais uma vez, manejar de forma satisfatória os dois tipos de transferência, para dar conta do material inconsciente por elas revelado.

A contratransferência não foi diferente em relação à transferência: inicialmente também foi avaliada como indesejável ao processo analítico e algo a ser superado para o sucesso da análise. De acordo com Melo, Magalhães e Féres-Carneiro (2014), trata-se de um conjunto de reações inconscientes do analista à transferência do paciente. Atualmente, o fenômeno da contratransferência é avaliado como uma importante ferramenta para a compreensão do paciente e as intervenções do analista, pois a proposta é que o inconsciente do analista entenda o inconsciente do paciente.

Em relação a esses fenômenos na clínica com casais, Correa (1992) aponta que a proposta da terapia de casal ou família é a análise grupal, situação esta que implica um enquadramento e uma escuta psicanalítica que favoreça a transferência. Sendo assim, "o enquadramento do trabalho que opera como continente do vínculo terapêutico significa no caso do referencial analítico uma decodificação do conteúdo latente em termos do que está sendo simbolizado ou transferido a partir da técnica interpretativa" (Correa, 1992 , p. 63). Isto é, o processo da transferência em terapia de casal ou família pode ser definido como o denominador comum das fantasias dos membros e dos afetos ligados a um objeto do passado do grupo envolvido e referidos por deslocamento e projeções ao terapeuta, que vai utilizar da técnica interpretativa como auxílio na elaboração das questões do grupo (Correa, 1992).

O fenômeno da transferência muitas vezes é considerado um obstáculo à terapia, principalmente quando esta ocorre de forma negativa. No entanto, de forma geral, o fenômeno se dá principalmente em relação ao analisando, enquanto o processo da contratransferência convida o terapeuta a refletir sobre sua subjetividade, já que o afeta diretamente. Correa (1992) ainda aponta que o fenômeno da contratransferência é interessante na análise de família ou casal, pois as questões destes podem suscitar no analista sentimentos referidos às suas próprias questões - ponto cego do analista - gerando dificuldades na terapia. Por isso, enfatiza 
a necessidade do terapeuta ter sua análise pessoal e uma supervisão clínica, principalmente no início da atuação profissional. Para Melo et al. (2014), mais do que isso, a contratransferência deve ser usada como um recurso terapêutico. Ou seja, aquilo que é comunicado pelo grupo ressoará contratransferencialmente no terapeuta que, por sua vez, poderá entrar em contato com aspectos secretos ou inconscientes do grupo quando tem a disponibilidade de analisar seus próprios conteúdos mobilizados, acessando a essência do que está sendo comunicado.

\section{Método}

Trata-se de um estudo teórico-clínico (Rodrigues, Sei, \& Arruda, 2013; Telles, Sei, \& Arruda, 2010), delineado a partir do estudo de caso, estratégia que, para Peres e Santos (2005), favorece uma análise mais pormenorizada do objeto em questão. Com isso, visa-se aqui discorrer sobre a psicoterapia psicanalítica de casal, a partir de um caso clínico atendido no contexto de um serviço-escola de Psicologia, compreendendo-se que tal proposta se justifica diante do número escasso de trabalhos que trata do processo terapêutico decorrente da terapia de casal (Ferreira, 2005).

Esclarece-se que esta investigação se insere em um projeto de pesquisa que visa investigar processos e fenômenos implicados no atendimento institucional, tendo sido aprovado pelo Comitê de Ética em Pesquisa da universidade na qual o estudo foi realizado, com assinatura do Termo de Consentimento Livre Esclarecido (TCLE) pelos participantes.

\section{Resultados e Discussão}

O casal que pretendemos apresentar e analisar a dinâmica iniciou a psicoterapia via demanda familiar. A família iniciou a psicoterapia no serviço-escola de Psicologia de uma universidade do interior paranaense, por meio da inserção em um projeto de extensão de atendimento a casais e famílias ofertado pela instituição. A queixa inicial trazida pelo grupo familiar relacionava-se com o "estresse" familiar, localizando a demanda no filho mais velho do casal, dado o fato deste apresentar alguns comportamentos julgados como inadequados pelos pais.

A família é composta pelo pai, Augusto ${ }^{1}$, com aproximadamente 50 anos, a mãe, Suzana, aproximadamente 15 anos mais jovem que 0 marido, e os dois filhos do casal, Eduardo de 10 anos e Mariana, com seis anos. Na época do atendimento, Augusto estava em sua terceira união, tendo três filhos advindos de seu primeiro casamento e um 
filho de sua segunda união. Augusto estava casado com Suzana há aproximadamente 12 anos, sendo que esta relação, assim como a segunda de Augusto, iniciou como fruto de uma traição dele.

Iniciaram a terapia muito mobilizados pelo filho mais velho, este claramente colocado em sessão como o "paciente identificado" (Dias, 1990). Todos pareciam muito animados e envolvidos com a terapia, menos Eduardo que, visivelmente, sentia-se incomodado em estar no setting. As atividades realizadas em sessão foram voltadas, em geral, para a família, no intuito de tirar o foco do menino e trabalhar as questões da família como um todo.

No entanto, com a terapia em curso com aproximadamente seis sessões, a terapeuta teve de se ausentar e à outra remeteu-se tal função. Após a inserção da segunda terapeuta, avaliou-se que seria interessante uma reorganização do setting, transformando 0 atendimento em uma terapia de casal. Tal modificação foi decorrente da menção a queixas como os ciúmes de Augusto em relação à Suzana, e a passividade desta em relação a querer trabalhar e não poder em função da casa e dos conflitos com o marido, segundo ela. Desta forma, notou-se que alguns sintomas aparentes em âmbito familiar descendiam de conflitos instaurados a partir do casal e que os sintomas apresentados pelas crianças, principalmente por Eduardo, eram consequência desses conflitos. Percebeu-se que possuíam muito mais conflitos em relação à conjugalidade, que à parentalidade.

A configuração da família não se restringia apenas aos quatro membros: a casa em que moravam era da mãe de Augusto - Fátima e esta, uma senhora idosa e doente, morava em espaço anexo à casa. Mais que gerar implicações de âmbito familiar, Fátima tomava tempo e demandava atenção de todos os membros da família, principalmente de Augusto. Quanto à rotina familiar, não havia muita organização: Suzana não trabalhava e, teoricamente, cuidava da casa e da agenda de Augusto, que dizia ser muito desorganizado com suas coisas. Este parecia viver em estado de ansiedade intensa por estar sempre "correndo" no cotidiano com assuntos referentes ao seu trabalho, tarefas de casa, além de colaborar com tarefas de sua esposa e de seus filhos - que faziam inúmeras atividades. Suzana deixou de dirigir após o casamento e deixava de executar certas atividades em casa, o que acabava sobrecarregando Augusto. As crianças não possuíam horário para dormir, e Augusto e Suzana sofriam algumas dificuldades em estabelecer limites às mesmas. Possuíam opiniões muito diferentes no que se referia à educação dos filhos, interferindo e desautorizando o discurso um do outro.

Apesar dos conflitos em relação à parentalidade e à conjugalidade, assim que passaram a compor um setting de casal, Augusto e Suzana demonstraram ter dificuldades de falar diretamente sobre eles enquanto casal. Alguns fatores apareciam repetidas vezes durante as 
sessões, em que ora serviam para se desvencilharem da análise, ora para contar algo do funcionamento deles: falavam frequentemente sobre a mãe de Augusto, sobre seus outros filhos e suas ex-esposas, além de outros fatores relacionados às crianças, como o futebol de Eduardo e seus meandros. Na maioria das sessões, Augusto monopolizava o discurso, deixando Suzana como espectadora ou comentadora. Muitas vezes, a terapeuta teve que intervir e convidar Suzana para participar da sessão. Ou seja, evidenciava-se no casal uma forte resistência à mudança.

Em relação à organização do casal, conforme definem Donnamaria et al. (2010), notava-se certas particularidades, que podemos entender como sintomas: no que se refere à cotidianidade, o casal possuía uma convivência diária escassa, visto que Augusto saía para trabalhar antes de Suzana acordar e os dois não tinham uma rotina conjunta; além disso, ambos não dormiam juntos, o que dificultava os momentos a dois. Não ficando juntos, tinham poucas relações sexuais. No entanto, mesmo com as dificuldades enfrentadas, Augusto e Suzana relatavam manter um vínculo monogâmico.

As funções de ambos enquanto casal e enquanto membros da família não eram claras, visto que a esposa ajudava o marido em relação a seus compromissos e este colaborava realizando tarefas que a esposa poderia realizar, causando conflitos entre os dois.

Ainda sobre a dinâmica do casal, vale ressaltar que a relação dos dois sempre fora atravessada por um terceiro elemento: seja a mãe de Augusto, os filhos ou a própria terapeuta. É o que os autores supracitados denominam de terceridade limitada, isto é, a estrutura do casal não se mantém autossuficiente e torna-se necessária a inserção de um terceiro que pode ocupar inúmeras posições. Em relação à Fátima, mãe de Augusto, esta tomava grande tempo e espaço da relação dos dois que, mesmo não estando na presença da mesma, costumavam falar sobre ela e enquadrá-la em inúmeras situações - principalmente em sessão, onde mantinham-se ocupados falando sobre Fátima por longo tempo. Os filhos pareciam manter um pilar tanto sobre a sustentação da família, quanto sobre a relação do casal, que estreitava suas funções enquanto pais e distanciavam-se enquanto cônjuges. Por vezes a terapeuta também se encaixou como o terceiro da relação, como em situações em que um saía da sala e o outro continuava falando sobre os dois - tentando manter certa confidencialidade com a terapeuta -, ou quando um dos dois ligava para comunicar algo que o outro não sabia e isso teria de ser discutido em sessão posteriormente.

Dentre os assuntos tratados, pôde-se entender um pouco do funcionamento do casal por meio de suas histórias. Augusto foi criado dentro de um ambiente um tanto conturbado: sofreu com alguns problemas de saúde quando criança, conviveu em meio à traição dos pais, além de crescer - como este mesmo apontou - com uma mãe 
"desequilibrada" psiquicamente. Os problemas de relacionamento com esta se mantiveram no presente, pois, além de estar debilitada fisicamente, mostrava-se psiquicamente da mesma forma.

Como dito, Augusto casou-se por três vezes e possuía seis filhos; cada uma de suas três filhas do primeiro casamento moravam em lugares diferentes e longe de Augusto, que tinha maior proximidade com a filha mais jovem. Possuía muitos conflitos com a filha mais velha que apresentava posicionamentos muito contrários aos do pai, fato que gerava discussões e desentendimentos. Com o filho de sua segunda união, nomeado como o pai, matinha uma boa relação: este já havia morado com o casal por um tempo e Augusto teve mais contato em sua educação. Nas duas primeiras uniões, Augusto manteve-se traindo suas esposas praticamente durante todo 0 casamento, com afirmações de que o atual relacionamento não era marcado por traições. Já passara por um episódio depressivo enquanto estava em seu antigo trabalho e receava voltar a ter tal crise. Na mesma época, teve crises de ansiedade, com sentimento de medo de morrer. Ultimamente estava lidando melhor com esta situação, porém, já fazia um tempo que ficava extremamente ansioso e fazia uso de medicação antidepressiva.

Suzana casou-se apenas uma vez, com Augusto, e nunca esteve em outra união estável. Vem de uma cidade de pequeno porte e, desde que se mudou para a cidade na qual habitava no momento do atendimento, passou a estudar e a morar sozinha, desenvolvendo uma vida independente. Após o casamento, segundo ela, tudo mudou: acomodou-se, rendeu-se aos ciúmes de Augusto e passou a ficar em casa, principalmente após o nascimento de Eduardo. Não possuía amigos e tinha uma grande dificuldade em se relacionar, tendo conflitos principalmente com a mãe e a irmã, que moravam em outra cidade. Sempre teve muito apreço por seu pai, que faleceu no ano anterior ao início da terapia, luto que parecia ainda não elaborado por ela. Sua família, assim como a de Augusto, era marcada por um histórico de traições: seu pai trabalhava fora da cidade e por vezes recebia ligações de mulheres em sua casa. Percebe-se que Suzana se incomodava um pouco quando Augusto falava de seus antigos casamentos e traições, porém, revelava satisfação por ser a mulher com a qual ele esteve mais tempo e sem traí-la.

Como apontado, no início da terapia, Suzana trouxe como demanda o ímpeto de trabalhar, mas apresentava certa ambivalência em relação a isso, alegando principalmente o ciúme de Augusto (que por vezes negou ciúmes exagerado) e por não poder mais conviver com os filhos, já que ficaria fora de casa o dia todo. Após uma intervenção da terapeuta sobre o fato - em que esta questionou Suzana sobre o real desejo desta trabalhar de fato, fazendo contrapontos entre desenvolver sua vida pessoal e profissional por meio do trabalho, ou 
continuar cuidando da casa, do marido e dos filhos -, a paciente revelou em outra sessão ter pensado melhor sobre o assunto, e deixou de fazer menção sobre o possível desejo de trabalhar.

O casal, de modo geral, possuía dificuldades em relação à conjugalidade. Augusto não ficava muito tempo em casa por conta do trabalho, convivia mais com as crianças e ficava madrugada afora trabalhando em casa. Enquanto isso, Suzana dormia sozinha na cama de casal e Augusto dormia no sofá. Outras vezes, Augusto dormia na cama das crianças, ou estas com a mãe na cama de casal. Pareciam não dialogar muito entre si e utilizavam o espaço da terapia para tal, deixando a terapeuta, por vezes, aquém da sessão. Percebe-se que construíram um vínculo muito mais de caráter parental que conjugal. Apontavam a vida sexual como algo positivo na vida de casados, contudo, alegavam que não possuíam tempo, tampouco oportunidades, reservando um curto tempo da semana para dedicarem-se a esta atividade. Relataram sentirem falta da convivência um do outro enquanto "marido e mulher", de sair, de dedicarem-se mais à relação, mas justificavam suas dificuldades em função da configuração familiar.

Levando em consideração os aspectos inconscientes que os mantinham unidos, pode-se perceber heranças psíquicas de ambos marcadas por uma forte transmissão psíquica transgeracional: a traição dos pais. Augusto aponta um padrão de repetição de seu pai ao casar-se várias vezes, traindo suas esposas. Contudo, no casamento com Suzana afirmava manter fidelidade, além de procurar agir de forma diferente com ela e os filhos. Augusto demonstrou ser mais responsável quanto ao casamento - não permanecendo fora de casa como fazia antes e não se encontrando com outras mulheres; e aos filhos - convivendo com os dois mais novos e participando efetivamente da educação dos dois, visto que em seus antigos casamentos ele não manteve o mesmo posicionamento diante dos outros filhos. Entende-se, no entanto, que esse movimento não era decorrente de elaborações, mas de uma tentativa imposta a si mesmo, o que gerava vários sintomas - o estresse, as crises de ansiedade, as sensações de enfarte. Suzana, por outro lado, mantinha uma boa relação com o pai, o estimava muito e suspeitava que este traía sua mãe, que se posicionava omissa. Da mesma forma, acabou escolhendo para casar-se um homem com histórico de traições, sendo ela uma dessas mulheres, e entende-se assim que seu mecanismo inconsciente provavelmente viu em Augusto a possibilidade de atuar seu desejo edípico de ser a "escolhida" do pai. 


\subsection{Análise sobre a dinâmica do casal e o trabalho do manejo terapêutico}

Embora tenham estabelecido em sessão um modo de se comportar que remete à resistência do casal, buscando com frequência trazer ao setting questões alheias ao relacionamento deles, tratava-se de um casal que quase não faltava, e que permaneceu por 14 meses em processo terapêutico. Possuíam um bom vínculo com a terapia e aparentavam ter desenvolvido uma transferência positiva com a terapeuta.

Com frequência, a terapeuta se sentia perdida em meio às malhas que eles a convidavam a entrar: problemas com a mãe do colega do futebol do filho, com a filha mais velha de Augusto, com a mãe dele, etc. Contratransferencialmente podia-se compreender o modo como se organizava a dinâmica deste casal: a sensação da terapeuta era de confusão, ela tinha dor de cabeça, ficava desanimada e sem esperança quanto ao futuro da terapia. Ou quanto ao futuro do casamento?

Contudo, havia uma preocupação em fazê-los dar-se conta de que a terapia existia para que conseguissem refletir sobre a relação conjugal, o fato de pouco conversarem, suas dificuldades na organização da rotina familiar, o que incluía o marido dedicar-se aos filhos à noite e a esposa ir dormir sozinha. Após a mãe de Augusto ter sido internada numa casa de repouso para idosos, o assunto da terapia voltou para o filho, o paciente identificado no início do tratamento - retratando a resistência que o casal possuía de trabalhar suas questões em terapia. A terapeuta apontou isso aos dois, e eles dando-se conta, conseguiram passar a conversar sobre os conflitos conjugais. Retomaram o ciúme existente entre eles, o que se entende que impedia esta mulher de dedicar-se à própria vida de forma mais legítima, sentindo-se mais viva, seguindo seus interesses. Ela quase não saía de casa, nem para levar os filhos ao colégio. Augusto tomava todas as iniciativas quanto a isso e não se queixava. $\mathrm{Na}$ sessão que conseguiam se dedicar ao assunto, Suzana não conseguia se colocar, passava a maior parte da sessão quieta e aparentemente com raiva. Augusto assumia um discurso de homem que se interessava em saber o que ela pensava, aparentando ser bastante compreensivo com ela, mas afirmava isso num discurso que soava quase imperceptivelmente contraditório.

Augusto e Suzana, na maioria das sessões, tinham dificuldades de imergir em seus assuntos e procuravam, de todas as formas possíveis, desviarem das questões que lhe competiam enquanto casal. Além de sempre terem um assunto diferente para tratar durante a sessão, também convidavam a terapeuta a desviar-se do que realmente importava. Aproveitando-se da transferência positiva e do forte vínculo que haviam estabelecido com a analista, 
desdobravam-se para seduzi-la em seus diversos acontecimentos diários e irrelevantes. Em conluio, ambos se desviavam de suas principais questões e convidavam a terapeuta a participar, que por vezes sentia-se imobilizada. A terapeuta tinha de ficar atenta aos movimentos contratransferenciais e 0 que deles emergiam. Entendemos que a resistência deles se compreendia face a um medo inconsciente de que o casamento não sobrevivesse caso pactos inconscientes viessem à tona e fossem trabalhados em terapia.

Retomando o pacto denegativo (Kaës, 2005), a dinâmica que este casal assumia faz pensar que se uniram a fim de lidar com as traições da história familiar de ambos. Este pacto existia para que cada um da dupla se beneficiasse, organizando a dinâmica psíquica inconsciente de forma que se mantivesse sob recalque aquilo da história de cada um que não encontrasse possibilidade de ser elaborado ainda nos psiquismos individuais. Tudo levava a crer que assumiam uma relação em que a esposa não trabalhava fora de casa para que não houvesse possibilidade de encontrar um possível amante. Assim, o marido sentia mais confiança no vínculo e não a traía. Em contrapartida, pelo fato dela abrir mão de sua vitalidade e do prazer de trabalhar, ele se esforçava, trabalhava dobrado para dar conta do orçamento familiar e para que não the sobrasse nenhum incômodo com os filhos, fazendo quase todas as tarefas em nível parental, e ela ficava somente organizando sua agenda. Desta forma, tudo seguia aparentemente bem, num discurso em que não se percebia demanda para a terapia, mas tratava-se de um casal que se organizava em torno da patologia, de deixar sob recalque aquilo que os incomodava psiquicamente.

Portanto, estamos diante de um casal que se vinculou muito mais em prol de um acordo inconsciente do que de construir um vínculo prazeroso, saudável, que fizesse sentido. Assim, havia um grande risco de que se separassem, mesmo em função da terapia de casal, pois quando sentissem que não precisariam mais um do outro para dar conta daquilo que sozinhos ainda não conseguiam (as traições do passado familiar), provavelmente o vínculo conjugal deixaria de fazer sentido já que não conseguiram construir uma vida em conjunto que sustentasse este vínculo para além da patologia. Daí vem, provavelmente, a demanda ambivalente para a terapia: sentiam esperança de encontrar uma saída, por meio da terapia, para a sensação de que o vínculo podia se perder - tal como a terapeuta sentia na contratransferência -, mas intuíam que era também por meio da terapia que poderiam chegar à conclusão de que o vínculo não tinha mais sentido. Ou seja, caso a terapia desse margem para que conseguissem elaborar o tema das traições familiares, esta temática poderia encontrar resolução para ambos, ou para um deles, mas o resultado seria o mesmo: perder-se a âncora que os segurava juntos. Restaria a eles conseguir ou não construir outra, mais 
saudável, baseada em projetos em conjunto, em parceria, para continuarem unidos.

Entende-se que o caminho que poderia uni-los era o mesmo que poderia separá-los. E não dependeria da terapeuta realizar o traçado deste caminho para um percurso ou outro, mas deles. Restava a ela somente alertá-los disso tudo. O espaço da terapia também poderia ser aquele de construir um novo vínculo sobre bases mais saudáveis. O casal permaneceu em atendimento por aproximadamente 14 meses, havendo poucos intervalos entre uma sessão e outra, visto que eram assíduos à terapia. Encerrou-se pela saída da terapeuta do serviço-escola e com a proposta de um novo encaminhamento.

\section{Considerações finais}

Muitas vezes quando um sujeito ou grupo busca atendimento por determinadas demandas, nem sempre suas questões são reveladas de início. Neste sentido, com o passar das sessões pode-se obter uma compreensão que direciona o olhar para outras questões, cabendo ao terapeuta avaliar qual rumo deve tomar a terapia. Foi assim que ocorreu com o caso de Augusto e Suzana: ao procurarem por terapia familiar afirmando haver dificuldades em relação à parentalidade e à configuração familiar, acabou-se optando por transformar este espaço em uma terapia de casal, devido às suas questões em relação à conjugalidade. Observava-se que muito do que não era resolvido pelos dois afetava as crianças, principalmente o mais velho, Eduardo, que pouco conseguia se comunicar, possuía dificuldades na escola e de comportamento.

A terapia de casal, assim como a individual, é repleta de desafios e de inúmeros fenômenos. Augusto e Suzana iniciaram o atendimento na esperança de encontrar uma saída para a sensação de que o vínculo podia se perder, mas intuíam que era também por meio da terapia que poderiam chegar à conclusão de que o vínculo não tinha mais sentido. A partir disso, o trabalho possível com a terapeuta foi o de refletir sobre a dinâmica do casal, sobre o que os unia, porque se mantinham juntos, o que era deles e o que não os pertencia, abordando até mesmo suas vidas anteriores ao casamento e seus vínculos familiares, tendo por base que o processo da transmissão psíquica transgeracional é atuante na formação de uma nova família. Caso a terapia tivesse conseguido levá-los a elaborar o tema das traições familiares, esta temática poderia encontrar resolução para ambos, ou para um deles, mas o resultado seria o mesmo: perder-se a âncora que os segurava juntos.

A análise deste caso faz pensar em como são complexos o funcionamento e a dinâmica de um casal, tomando por base os processos conscientes e inconscientes que os mantém juntos, ainda 
que de forma não saudável. E, diante disso, o quanto é árdua a tarefa do terapeuta de casal, principalmente quando este é um estagiário de psicologia, como neste caso. Nem sempre, por mais cuidadoso que seja, um trabalho como esse alcança um resultado completamente favorável, como se espera, já que são muitos os meandros que circundam e determinam o caminhar do processo terapêutico. Contudo, pensa-se que ainda assim o tempo em terapia foi benéfico a esse casal, pois puderam se apropriar de suas demandas conscientes e inconscientes, entender os motivos, ainda que parcialmente, que os mantinham juntos, semear um espaço para pensarem no vínculo que construíram. Ou seja, houve um trabalho e esse é, na verdade, o principal objetivo de uma terapia, pois desta conhecemos apenas as regras iniciais do jogo.

\section{Referências}

Benedito, V. L. Y. (2004). Abordagem simbólica do conflito conjugal: o corpo em cena. In M. A. F. Vitale (Org.). Laços amorosos: terapia de casal e psicodrama (pp. 83-100). São Paulo: Ágora.

Correa, O. R. (1992). Aspectos da transferência e contratransferência na abordagem psicanalítica do grupo familiar e casal. In $\mathrm{M}$. Ramos. (Org.), Terapia de casal e família: o lugar do terapeuta (pp. 61-71). São Paulo: Editora Brasiliense.

Correa, O. B. R. (2004). Transmissão psíquica entre as gerações. Psicologia USP, 14(3), 35-45.

Dias, M. L. (1990). O que é psicoterapia de família. São Paulo: Editora Brasiliense.

Donnamaria, C. P., Nascimento, F. R. M., \& Terzis, A. (2010). Vínculos conjugais na contemporaneidade: revisitando parâmetros definitórios. Vínculo, 1(7), 01-11.

Féres-Carneiro, T. (1994). Terapia de casal: ruptura ou manutenção do casamento? Temas em Psicologia, 2, 37-52.

Féres-Carneiro, T., \& Diniz-Neto, O. (2008). Psicoterapia de casal: modelos e perspectivas. Aletheia, 27(1), 173-187.

Ferreira, V. R. T. (2005). Produção brasileira em bases de dados sobre o processo terapêutico na terapia familiar e de casal. Psico(PUCRS), 36(1), 7-12.

Freud, S. (1966). Sobre o Narcisismo: Uma Introdução. Obras completas. Edição Standard Brasileira, vol. XIV. Rio de Janeiro: Imago. (Original de 1914)

Gomes, I. C, \& Levy, L. (2010). Indicações para uma terapia de casal. Vínculo, 1(7),01-81.

Gutierrez, D. M. D., Castro, E. H. B., \& Pontes, K. D. S. (2011). Vínculo mãe-filho: reflexões históricas e conceituais à luz da 
Psicanálise e da Transmissão Psíquica entre gerações. Revista do Nufen, 1(2), 3-24.

Isolan, L. R. (2005). Transferência erótica: uma breve revisão. Revista Psiquiatria, 27(2), 188-195.

Kaës, R. (1991). El Pacto Denegativo en los conjuntos transsubjetivos. In A. Misseranrd et al, Lo negativo. Figuras $y$ Modalidades (pp. 130-168). Buenos Aires: Amorrortu.

Kaës, R. (2001). O sujeito da herança. In R. Kaës; H. Faimberg et al. (Orgs.), Transmissão da vida psíquica entre gerações (pp. 925). São Paulo: Casa do Psicólogo.

Kaës, R. (2005). La structuration de la psyché dans le malaise du monde moderne. Etudes, recherches, actions en santé mentale en Europe, 1, 239-256.

Kaës, R. (2011). Um singular plural: a psicanálise à prova do grupo. São Paulo: Edições Loyola.

Levy, L. (2013). A resistência na clínica com casais. In I. C. Gomes, \& L. Levy. (Orgs.), Atendimento psicanalítico de casal (pp. 2942). São Paulo: Zagodoni.

Melo, C. V; Magalhães, A. S, \& Féres-Carneiro, T. (2014). Segredos de família: a contratransferência como recurso terapêutico. Estilos da clínica, 19(1), 163-182.

Merli, L. F. (2012). Quando a parentalidade surge antes que a conjugalidade. (Dissertação de mestrado). Instituto de Psicologia de São Paulo, São Paulo.

Peres, R. S., \& Santos, M. A. (2005). Considerações gerais e orientações práticas acerca do emprego de estudos de caso na pesquisa científica em Psicologia. Interações, 10(20), 109-126.

Pimentel, C. B., \& Barros, I. P. M. (2009). Transferência e desfecho terapêutico em psicoterapia psicodinâmica breve. Psicologia: Teoria e prática, 11(1), 142-152.

Puget, J., \& Berenstein, I. (1993). A psicanálise do Casal. São Paulo: Artes Médicas.

Rodrigues, F. P. H., Sei, M. B., \& Arruda, S. L. S. (2013). Ludoterapia de criança com Síndrome de Asperger: estudo de caso. Paidéia (USP. Ribeirão Preto. Impresso), 23(54),121-127.

Telles, J. C. C. P., Sei, M. B., \& Arruda, S. L. S. (2010). Comunicação silenciosa mãe-bebê na visão winnicottiana: reflexões teóricoclínicas. Aletheia (ULBRA), 33, 109-122.

Ventura, R. (2009). Os paradoxos do conceito de resistência: do mesmo à diferença. Estudos de Psicanálise, 32, 153-162.

Winnicott, D. W. (1963). O ambiente e os processos de maturação: estudos sobre a teoria do desenvolvimento emocional. Porto Alegre: Artmed. 


\section{Endereço para correspondência Natalia Monti Di Osti}

Universidade Estadual de Londrina - UEL

Rodovia Celso Garcia Cid - PR-445 Km 380, Campus Universitário, Caixa-postal 10011, CEP 86057-970, Londrina - PR, Brasil

Endereço eletrônico: nataliadiosti@gmail.com

\section{Maíra Bonafé Sei}

Universidade Estadual de Londrina - UEL

Rodovia Celso Garcia Cid - PR-445 Km 380, Campus Universitário, Caixa-postal 10011, CEP 86057-970, Londrina - PR, Brasil

Endereço eletrônico: mairabonafe@gmail.com

\section{Sandra Aparecida Serra Zanetti}

Universidade Estadual de Londrina - UEL

Rodovia Celso Garcia Cid - PR-445 Km 380, Campus Universitário, Caixa-postal 10011, CEP 86057-970, Londrina - PR, Brasil

Endereço eletrônico: sandra.zanetti@gmail.com

Recebido em: 03/08/2015

Aceito para publicação em: 24/09/2016

\section{Notas}

${ }^{1}$ Os nomes adotados são fictícios.

* Psicóloga, Especialista em Saúde Mental pela Universidade Estadual de Londrina (UEL).

** Psicóloga, Mestre, Doutora e Pós-Doutoranda em Psicologia Clínica pelo Instituto de Psicologia da Universidade de São Paulo (IP-USP).

*** Psicóloga, Mestre, Doutora e Pós-Doutora em Psicologia Clínica pelo Instituto de Psicologia da Universidade de São Paulo (IP-USP). 